\title{
Vulnerability analysis of future public water supply under changing climate conditions: A study of the Moy catchment, western Ireland
}

\author{
Julia Hall, Conor Murphy \\ Irish Climate Analysis and Research UnitS (ICARUS), Department of Geography, \\ National University of Ireland Maynooth, Co. Kildare, Ireland
}

\author{
Corresponding author: \\ Julia Hall \\ Email: Julia.Hall@nuim.ie
}

\begin{abstract}
An application of the Water Evaluation and Planning tool Version 21 (WEAP21) is developed to analyse the vulnerability of the future public water supply in the River Moy catchment, western Ireland. The River Moy's future hydrology is modelled using the WEAP21 integrated rainfall runoff module and an ensemble of statistically downscaled future climate series. This approach facilitates the identification of the most vulnerable future public water supplies without being constrained by the availability of historically observed streamflow records. The model is calibrated by linking the model-independent parameter estimation tool (PEST) with the hydrological model and verified by reproducing observed streamflow records. This research suggests an emerging vulnerability to water stress of the public water supply sector under the four modelled scenarios, for areas which currently have plenty of water available. These results present a basis for future planning and management of the Moy catchment and its water resources.
\end{abstract}

\section{Key words:}

Climate change; Ireland; PEST; public water supply; vulnerability assessment; water stress; WEAP21 


\section{Background}

Following the Intergovernmental Panel on Climate Change's (IPCC) Fourth Assessment Report (AR4), there is a general consensus that the Earth's climate system is changing (IPCC 2007). Additionally, the IPCC states in its latest assessment "Climate Change and Water" (Bates et al. 2008) that the climate warming observed over the past several decades is consistently associated with changes in a number of components of the hydrological cycle. For instance, changing precipitation patterns, intensity and extremes have been observed all over the world (Bates et al. 2008). Consequently, climate change has the potential to significantly alter river flow regimes in a river catchment. The consequences of climate change will be superimposed onto the normal weather variations that occur from year to year and onto inter-decadal climatic variations. Normal weather variability can either mask or amplify the climate change signal (Arnell 2006). Hence, the past will no longer be the key to the future in water resource planning and management, as historical river flows and groundwater recharge rates are likely to be altered by climatic change.

For Ireland, there have been a number of studies investigating the impacts of climate change on catchment hydrology. All studies consistently indicate increasing river flows in Ireland during winter and spring, as well as reductions in streamflow in late summer and autumn by the middle and end of this century (Charlton and Moore 2003; Cunnane and Regan 1994; Murphy and Charlton 2006; Steele-Dunne et al. 2008). Having identified these potential impacts of climate change on river flow, it is important to analyse and quantify these effects in a broader context. Therefore, this study builds on the results of previous research and aims to move the focus away from the first generation climate change impact assessment towards a more integrated simulation and assessment of water resources and water supply systems in a changing climate.

This study is the first investigation to include a broader range of factors and considers the implications of changing conditions for future water supply. Furthermore, the study catchment is analysed in a spatially refined way by investigating water supply vulnerability on the scale of individual urban areas, rather than the catchment as a whole. This enhancement allows for a more precise identification of vulnerability in the area of water resources, leading to the development and implementation of measures to reduce such vulnerability.

This is particularly important for Ireland, as it currently has the highest population growth rate within the EU (CSO 2009). The growing population will result in an increasing demand for public water. Crucially, there are no monetary incentives to reduce domestic water demand, as public water and sewage charges for domestic water use were abolished in 1997. Another challenge in the area of water supply is the currently high value of unaccounted for water in Ireland. On a national average, more than $43 \%$ of the processed water added to the supply system is currently lost due to leakages in an aging water infrastructure (Forfás 2008). To these existing and expected challenges, the effects of climatic change will be added. Climate change needs to be taken into account in future planning, as it has the potential to change the water availability in some regions.

This paper presents the application of the Water Evaluation and Planning model Version 21 (WEAP21) to the Moy catchment. WEAP21 is a tool for integrated catchment hydrology and water supply modelling, assessment and planning (Yates et al. 2005a,b). The Moy catchment was chosen for this study due to its location on the Irish western seaboard (1). In general, the west coast of Ireland receives higher average annual rainfall than most other Irish locations. It is of interest to investigate whether an area historically rich in water will be potentially vulnerable to future changing conditions with regard to its public water supply. 


\section{Study Site}

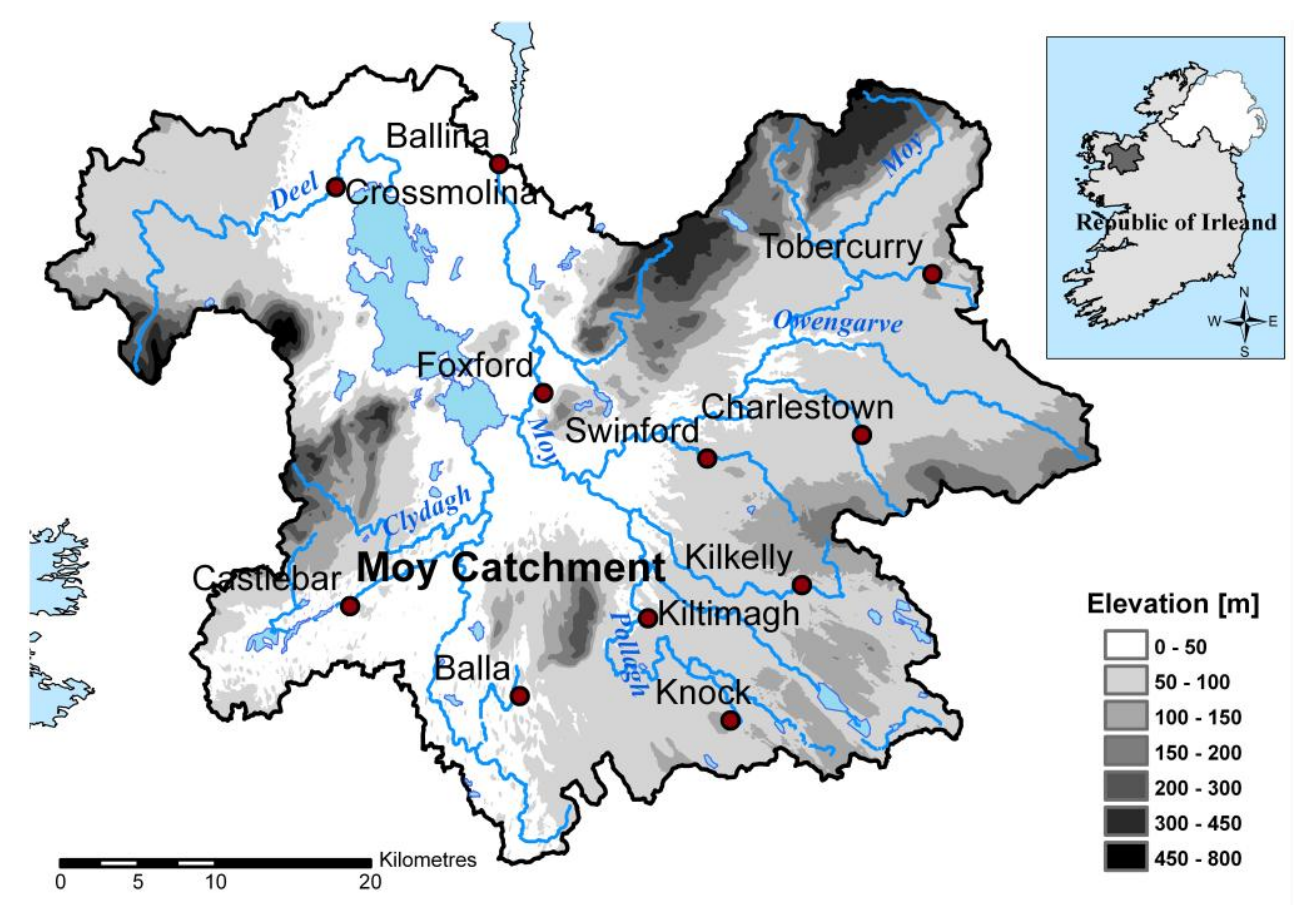

Fig.1 The Moy catchment, western Ireland

The River Moy catchment, shown in Figure 1, is located in the west of Ireland. The catchment area encompasses an area of $\sim 1980 \mathrm{~km}^{2}$ in a low-lying topographic region with altitude ranging between sea level and $800 \mathrm{~m}$. Only two upland areas have an elevation higher than 450 metres. The climate of the Moy region is dominated by the North Atlantic Ocean, as is the entire island of Ireland, and this results in a moist, temperate, maritime climate with no significant temperature extremes during winter (December to February) or summer (June to August). The dominant winds are south-westerly and originate from Atlantic depressions, which result in enhanced precipitation especially on the western coast of Ireland. For the Moy catchment, the average annual rainfall is $\sim 1140 \mathrm{~mm}$ (Met Éireann 2008). Therefore, plenty of water has always been available to supply the water needs of the region. Figure 2 shows an average monthly precipitation maxima of the Moy catchment can be measured during wintertime $(100-130 \mathrm{~mm})$ and minima in early summer $(60-80 \mathrm{~mm})$ (Met Éireann 2008). Figure 2 also illustrates the average streamflow of the Moy catchment measured at Rahans, before the River Moy enters the sea. The distinct flow pattern of the catchment is shown, with minimum average monthly streamflows at Rahans during summer ranging between $27-24 \mathrm{~m}^{3} / \mathrm{s}$ and winter flows varying between $90-105 \mathrm{~m}^{3} / \mathrm{s}$. Groundwater recharge rates are generally low with most of the catchment receiving 100-200 $\mathrm{mm}$ of replenishment per year or less (Working Group on Groundwater 2008).

The River Moy is a candidate Special Area of Conservation (SAC) selected for alluvial wet woodlands and raised bog, which are both priority habitats on Annex I of the E.U. Habitats Directive. The site is also a candidate SAC selected for three additional habitats listed on Annex I and four species listed on Annex II, such as the Atlantic Salmon (NPWS 2008). The River Moy system is one of the most important and productive waters for the Atlantic Salmon in Western Europe. Additionally, the two big lakes within the catchment, Lough Conn and Lough Cullin, are renowned for their trout fisheries. 


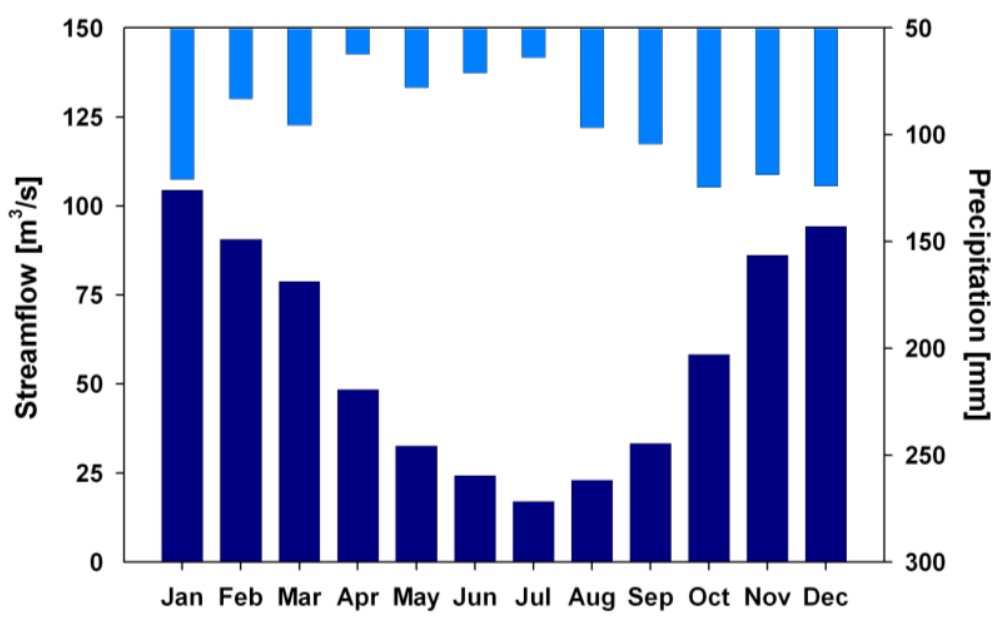

Fig. 2 River Moy mean monthly streamflow at Rahans and mean monthly precipitation at Claremorris, Ireland

The land cover of Moy catchment is characterised by high peat bog cover (35\%) as well as by pastures and woodlands (27\%) (O'Sullivan 1994). Less than $1 \%$ of the Moy catchment is covered by urban areas. The total population of the catchment was estimated as 70,000 in 2002 (Cycleau 2008), approximately $30 \%$ of which lived in 11 urban areas larger than 250 inhabitants. These urban areas were considered within the application of the WEAP21 model to be supplied by public water supplies.

Generally, Irish water services are not simple structures. The sector for drinking water supply displays a very complex pattern. While the European Communities Drinking Water Regulations No. 2 of 2007 specifies two broad categories of "public" and "private" water supply, the water supply structure in Ireland is provided by four different schemes: Public Drinking Water Supplies, Public Group Water Schemes, Private Group Water Schemes and Small Private Supplies. The majority of the Moy catchment's population is served by public water supplies (CSO 2006). The other three supply categories are regarded as "private" in the Regulation's legal sense. The sources of the provided water differ from place to place. Overall, the bulk of municipal drinking water $(83 \%)$ originates from surface water (lakes and rivers). Relatively small components of domestic drinking water originate from groundwater abstraction (11\%) and natural spring water (6\%) (EPA 2007). This study focused on direct abstractions from surface waters in the Moy catchment, as these are the ones most likely to be directly affected by a changing climate and in addition, had more robust model input data available than the other two water sources. 


\section{Methodology and WEAP21 Model}

The application of the WEAP21 model to the Moy catchment consisted of three major stages, each with several smaller steps: the hydrological model setup; the implementation of the current catchment conditions; and the future hydrological model with future water demand scenarios. This methodology is described in detail in the following sections.

\subsection{Hydrological Model}

In the first stage, the WEAP21 integrated rainfall runoff module of the Moy catchment was deployed to simulate the flows, which form the streamflow available for surface abstraction. The rainfall runoff model selected for this study was the 'Soil Moisture Method'. Within this hydrological routine, the catchment hydrology is represented by a two-bucket rainfall runoff model, which models the hydrological processes in two layers. Details on this hydrological routine can be found in Yates et al. (2005a). For the Moy catchment, no hydrological connection to groundwater was assumed, as recharge rates are low within the investigated catchment compared to surface runoff (Working Group on Groundwater 2008). Outflow of the model's lower layer is represented as river base flow.

Model performance was evaluated using two verification methods: a split-sample test and the transferability of model parameters (proxy-basin test) (Klemeš 1986). In the split-sample test, the available streamflow record was split into two segments with $70 \%$ of the record (16 years) used for model calibration (1973-1989) and the last $30 \%$ (1990-1996) for model verification. The hydrological model parameters were calibrated in four sub-catchments of the Moy catchment (Clydagh, Deel, Owengarve and Pollagh River). These sub-catchments, located on tributaries of the River Moy, were chosen due to their upstream location of major settlements. In testing the transferability of model parameters within the Moy catchment, the proxy-basin test was applied. Two catchments with similar characteristics are cross-checked during calibration and verification. The model is calibrated for one catchment and then run with the obtained parameter values in the other catchment for verification and vice versa.

To force the hydrological model, historical daily climate data (precipitation and temperature) and historical 30-year monthly averages for humidity, wind speed and sunshine hours were used. The data was taken from the synoptic weather station in Claremorris, which is located $\sim 5$ $\mathrm{km}$ to the south of Moy catchment. This synoptic station is the closest point to the catchment for which climatic data is available. Daily climate data was summed for each month to take account of the WEAP21 modelling time steps.

Initially, the hydrological model parameters shown in Table 1 were specified according to known sub-catchment characteristics. To get a better understanding of the processes represented in the WEAP21 integrated hydrological model a parameter sensitivity analysis was performed (Bahremand and De Smedt 2008). Generally, sensitivity is a measure of the effect of the change in one factor on another factor (Lenhart et al. 2002). To identify the model's sensitive parameters, the effect of each parameter was analysed with respect to the modelled streamflow. With the knowledge of how each individual parameter influences the model's behaviour, model parameters can be estimated better and the manual calibration process becomes faster. In this study, initial parameter estimates were made on sub-catchment characteristics extracted from GIS shapefiles and then one parameter was changed manually while the other parameters were held constant. The parameters were altered to their lower and upper limit (if identifiable). With the knowledge of model sensitivity, the hydrological model was then manually calibrated by forcing it with the observed precipitation and temperature data and comparing the modelled and observed streamflow. 
Table 1 WEAP21 parameters, their description, range and units

\begin{tabular}{|c|c|c|c|c|}
\hline \multicolumn{2}{|r|}{ Parameter } & \multirow[t]{2}{*}{ Parameter Description } & \multirow{2}{*}{$\begin{array}{l}\text { Monthly } \\
\text { Variation }\end{array}$} & \multirow{2}{*}{$\begin{array}{l}\text { Range } \\
\text { and Unit }\end{array}$} \\
\hline Abbr. & Full Name & & & \\
\hline $\mathrm{Kc}$ & $\begin{array}{l}\text { Crop/Plant } \\
\text { Coefficient }\end{array}$ & $\begin{array}{c}\text { Crop or plant coefficient for land } \\
\text { cover. }\end{array}$ & Yes & From 0 \\
\hline SWC & $\begin{array}{l}\text { Soil Water } \\
\text { Capacity }\end{array}$ & $\begin{array}{c}\text { Effective water storage capacity of } \\
\text { upper bucket (root zone). }\end{array}$ & Yes & $\begin{array}{l}\text { From } 0 \\
\mathrm{~mm}\end{array}$ \\
\hline DWC & $\begin{array}{l}\text { Deep Water } \\
\text { Capacity }\end{array}$ & $\begin{array}{c}\text { Effective Water Storage Capacity of } \\
\text { lower bucket. }\end{array}$ & No & $\begin{array}{l}\text { From } 0 \\
\mathrm{~mm}\end{array}$ \\
\hline RRF & $\begin{array}{l}\text { Runoff Resistance } \\
\text { Factor }\end{array}$ & $\begin{array}{l}\text { Controls surface response, influenced } \\
\text { by Leaf Area Index and slope. }\end{array}$ & Yes & 0.1 to 10 \\
\hline RZC & $\begin{array}{l}\text { Root Zone } \\
\text { Conductivity }\end{array}$ & $\begin{array}{l}\text { Upper bucket saturated conductivity. } \\
\text { Partitioned according to PFD between } \\
\text { interflow \& flow to lower bucket. }\end{array}$ & Yes & $\begin{array}{l}\text { From } 0.1 \\
\mathrm{~mm} / \text { time }\end{array}$ \\
\hline DC & $\begin{array}{l}\text { Deep } \\
\text { Conductivity }\end{array}$ & $\begin{array}{l}\text { Saturated conductivity of the lower } \\
\text { bucket (at } z 2=100 \%) \text {. Parameter } \\
\text { controls transmission of base flow. }\end{array}$ & Yes & $\begin{array}{l}\text { From } 0.1 \\
\mathrm{~mm} / \text { time }\end{array}$ \\
\hline PFD & $\begin{array}{l}\text { Preferred Flow } \\
\text { Direction }\end{array}$ & $\begin{array}{l}\text { Partitioning coefficient. Partitions flow } \\
\text { out of the upper bucket between } \\
\text { interflow and lower bucket. }\end{array}$ & Yes & 0 to 1 \\
\hline $\mathrm{z} 1$ & $\begin{array}{l}\text { Initial Relative } \\
\text { Storage z1 }\end{array}$ & $\begin{array}{l}\text { Relative Storage as fraction of total } \\
\text { capacity upper bucket. }\end{array}$ & No & 0 to $100 \%$ \\
\hline $\mathrm{z} 2$ & $\begin{array}{l}\text { Initial Relative } \\
\text { Storage z2 }\end{array}$ & $\begin{array}{l}\text { Relative Storage as fraction of total } \\
\text { capacity lower bucket. }\end{array}$ & No & 0 to $100 \%$ \\
\hline
\end{tabular}

During calibration, model performance was assessed using qualitative and quantitative techniques based on visual inspection of the model output (streamflow) and the use of objective functions to provide a numerical assessment of performance. Two objective functions (NashSutcliffe Efficiency Coefficient (NS) and Coefficient of Determination $\left(\mathrm{r}^{2}\right)$ ) are used to measure the errors between the simulated and modelled streamflows. Both provide a measure of the ability of a model to predict flows, which are different from the mean. NS can range from $-\infty$ to +1 with a value of 1 indicating a perfect fit. NS is sensitive to differences in modelled and observed means and variances but is also biased on higher flows due to the use of the sum of squared errors (Dawson and Wilby 2001). Therefore, performance was also tested using $r^{2}$ to assess the variance of the observed flow that can be explained by the model. $r^{2}$ is particularly sensitive to outliers in the data range but insensitive to additive and proportional differences between modelled and observed data. Thus, the model can return satisfactory values in the $r^{2}$ statistic even if the model always overestimates or underestimates the magnitude of observed data values (Dawson and Wilby 2001).

During manual calibration, a parameter optimisation process was applied in which several hydrological model parameters were adjusted, with the aim of achieving best fit between simulated streamflow and the observed average of monthly river flows. The two main weaknesses of manual calibration are that this approach can be very time consuming and can also have a high level of subjectivity, as the termination of parameter adjustment is based on individual decisions. It is possible that different researchers will obtain different parameter sets for the same modelled catchment (Sorooshian and Gupta 1995).

To minimise the subjectivity in the modelling process, WEAP21 was linked with a nonlinear and model-independent parameter estimation tool (PEST) to perform the automated parameter estimation (Doherty and Johnston 2003). 
Automated calibration with the help of PEST involves the application of a search algorithm (Gauss-Marquardt-Levenberg) to determine the model optimum parameters. During the automated parameter calibration process, model parameters are adjusted within a user pre-defined range until the sum of squares of the differences between modelled and measured streamflow values are reduced to a minimum. As PEST's search algorithm seeks for a local minimum, the manual parameter estimates were used as initial input values for the automated estimation process. Another benefit of using PEST over manual calibration is that PEST is able to perform the calibration on the actual monthly streamflow values instead of monthly averages used in manual calibration.
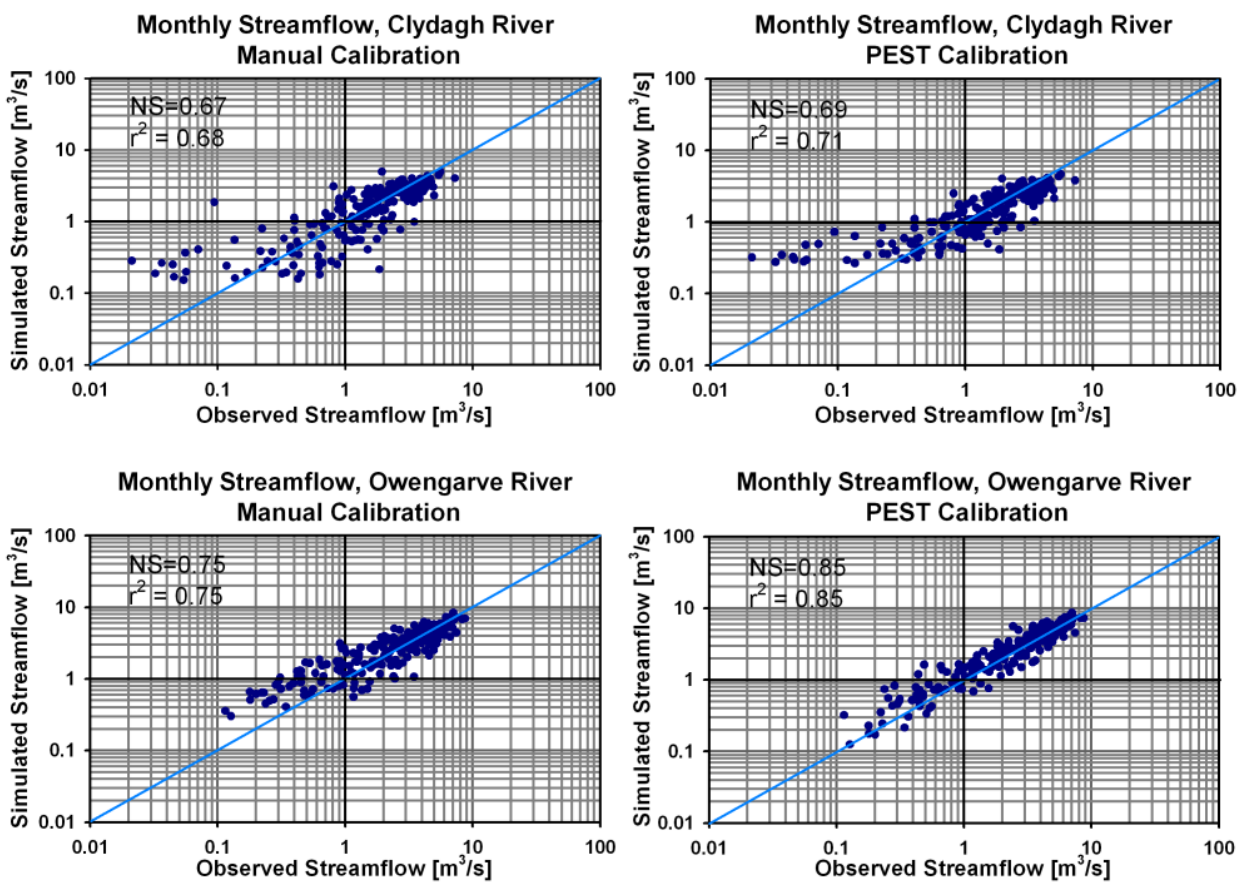

Fig. 3 Scatter plots of monthly streamflow and objective functions, after manual and automated calibration, for the Owengarve and Clydagh River

Figure 3 shows log-log scatter plots of the monthly-observed flow values against the simulated streamflow and the two objective functions (based on the manually obtained parameters and the PEST-estimated parameters shown in Table 2).

As can be seen in Figure 3, running the model with the manually calibrated parameters results in an overestimation of lower flows (mainly during summer months). After the automated calibration with PEST, the low flow predictions improved. This enhanced performance is particularly important for water resource assessment, as the low flows during summer time are most likely to cause supply shortages.

Since the model calibration was performed in sub-catchments of the River Moy, the transferability of parameter values between sub-catchments with similar land cover characteristics was established with the help of the proxy-basin test. There are two dominating land cover sub-types within the Moy catchment: sub-catchments principally covered by peat bogs and regions mainly covered by pastures and woodland. For these two land cover sub-types separate proxy-basin test were performed. 
Table 2 Manual and PEST calibration parameter values

\begin{tabular}{|c|c|c|c|c|c|}
\hline Parameter & $\begin{array}{c}\text { Manual } \\
\text { Owengarve } \\
\text { and Pollagh }\end{array}$ & $\begin{array}{c}\text { Final (PEST) } \\
\text { Owengarve } \\
\text { and Pollagh }\end{array}$ & Parameter & $\begin{array}{c}\text { Manual } \\
\text { Clydagh and } \\
\text { Deel } \\
\end{array}$ & $\begin{array}{c}\text { Final (PEST) } \\
\text { Clydagh and } \\
\text { Deel }\end{array}$ \\
\hline \multirow{2}{*}{ Kc } & \multirow{2}{*}{1.2} & \multirow{2}{*}{1.19} & $\mathrm{Kc}_{\mathrm{W}}$ & 0.10 & 0.10 \\
\hline & & & $\mathrm{Kc}_{\mathrm{S}}$ & 0.35 & 0.26 \\
\hline \multirow{2}{*}{ SWC } & \multirow{2}{*}{250} & \multirow{2}{*}{200.21} & $\mathrm{SWC}_{\mathrm{W}}$ & 10.00 & 73.06 \\
\hline & & & $\mathrm{SWC}_{\mathrm{S}}$ & 10.00 & 32.33 \\
\hline DWC & 250 & 370 & DWC & 250.00 & 280.31 \\
\hline \multirow{2}{*}{ RRF } & \multirow{2}{*}{5} & \multirow{2}{*}{2.76} & $\mathrm{RRF}_{\mathrm{W}}$ & 0.10 & 2.91 \\
\hline & & & $\mathrm{RRF}_{\mathrm{S}}$ & 5.00 & 4.52 \\
\hline \multirow{2}{*}{ RZC } & \multirow{2}{*}{120} & \multirow{2}{*}{79.38} & $\mathrm{RZC}_{\mathrm{W}}$ & 1.00 & 15.34 \\
\hline & & & $\mathrm{RZC}_{\mathrm{S}}$ & 50.00 & 65.80 \\
\hline \multirow{2}{*}{$\mathrm{DC}$} & \multirow{2}{*}{5000} & \multirow{2}{*}{1453.54} & $\mathrm{DC}_{\mathrm{W}}$ & 25.00 & 17.56 \\
\hline & & & $\mathrm{DC}_{\mathrm{S}}$ & 25.00 & 12.30 \\
\hline \multirow{2}{*}{ PFD } & \multirow{2}{*}{0} & \multirow{2}{*}{1} & $\mathrm{PFD}_{\mathrm{W}}$ & 1.00 & 0.77 \\
\hline & & & $\mathrm{PFD}_{\mathrm{S}}$ & 0.01 & 0.16 \\
\hline $\mathrm{Z} 1$ & 30 & 30 & Z1 & 100 & 100 \\
\hline $\mathrm{Z} 2$ & 30 & 30 & $\mathrm{Z} 2$ & 100 & 100 \\
\hline
\end{tabular}

For areas principally covered by peat, the two sub-catchments of the Clydagh and Deel River were selected. For the regions mainly covered by pastures and woodland, the Owengarve and Pollagh River were chosen for model calibration and verification. The hydrological routine was calibrated in the Clydagh and the Owengarve sub-catchments and verified on the other sub-catchments (the Deel and Pollagh), and vice versa. The sub-catchments pairs Clydagh and Deel River, and Deel and Pollagh River obtained slightly different parameter sets in their individual PEST calibration but overall the parameter values were of the same magnitude. These results suggest that the calibrated model parameters are transferable to other subcatchments with similar land cover characteristics within the Moy catchment.

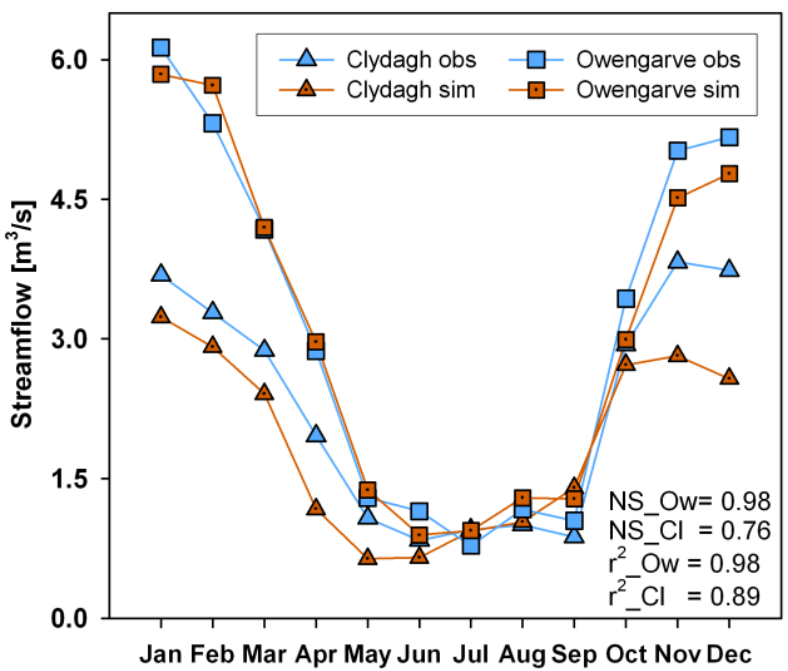

Fig. 4 Observed monthly mean streamflow of the Owengarve and Clydagh River against simulated over verification period 1990 to 1996

The two final parameter sets for the peat and pastures and woodland land cover used in the simulation were obtained by averaging the parameter sets obtained in the individual PEST calibrations (Table 1). This procedure further improved the objective functions in all four sub-catchments as shown in Table 2. The mean monthly streamflows for the Clydagh and Owengarve River of the verification period (1990-1996) are shown in Figure 4, indicating that 
the model is able to reproduce the low flows in summer time, which are of special interest to water managers.

Table 3 Water-Use-to-Resource-Ratio classes (Raskin 1997)

\begin{tabular}{ccccc}
\hline Use to Resource Ratio & $<10 \%$ & $10-20 \%$ & $20-40 \%$ & $>40 \%$ \\
\hline Stress Class & No Stress & Low Stress & Medium Stress & High Stress \\
\hline
\end{tabular}

For all sub-catchments, the calibration and verification resulted in satisfactory values for the objective functions. The simulated flows for the Clydagh and the Deel catchment returned lower values for NS (0.76 and 0.84) compared to the Owengarve and Pollagh catchment (both 0.98), indicating that the model is less successful at simulating processes within the peatdominated areas, especially during the winter months. Common features of peat lands are high water tables, low water-storage capacity and fast runoff generation due to saturation overland flow. Additionally, in deeper peat, pipe flow plays an important role in runoff generation (Evans and Warburton 2007). However, wetland characteristics will always be difficult to incorporate into a hydrological model as there is no simple relationship between wetland types and the hydrological function they perform (Bullock and Acreman 2003). Every peat-covered area will therefore exhibit different hydrological characteristics, where models might not be able to replicate with consistent accuracy. However, in this model the peat-dominated catchments are both above 0.7 in both the calibration and verification period, indicating a good model performance. A NS in excess of 0.6 indicates a satisfactory fit between observed and modelled data (Wilby 2005). Additionally the peat-dominated areas obtain a good score for $\mathrm{r}^{2}$, although the model tends to underestimate the winter and early spring flows in these areas. Despite these limitations, the results for the two objective functions indicate that both the model calibration and verification period of the WEAP21 model of the River Moy and its sub-catchment reproduces the streamflow characteristics and flow volumes sufficiently.

\subsection{Current Catchment Conditions}

The water supply and demand infrastructure of the Moy catchment was established with present water use data. To compute the surface water flows within the model, the Moy catchment was divided into contiguous sub-catchments. These sub-catchments were delineated according to their surface watershed with the help of a digital terrain model and a GIS. These sub-catchments cover the entire area of the study catchment. The extent of these subcatchments accounts for the area on which the precipitation accumulates to form surface water flows. This surface water is then delivered to one of the eleven examined urban areas. The urban areas were individually populated with their number of inhabitants obtained from the Central Statistics Office's Census 2006 (CSO 2006). The current average Irish per capita water demand is estimated to be 150 litres by Galway City Council (Slow the Flow 2009). The average water supply infrastructure losses account for $43 \%$ of the abstracted water (Forfás 2008). Leakages are modelled as increased water supply requirements. This implies that no water is lost from the system and all water is available for further use downstream.

\subsection{Future Hydrological Model and Climate Scenarios}

Upon successful calibration and verification of the sub-catchments, the model is able to simulate future streamflow of the catchment with future climate data input. Unchanged model parameters were used for future model runs, which is the predominantly applied approach in rainfall-runoff model environmental-change impact assessment, where possible feedback effects are not considered (Bronstert 2004). 
The River Moy's future hydrology, in terms of a single streamflow series, was modelled using a weighted ensemble of future climate series. The climate data used to force the WEAP21 hydrological model for future simulations were obtained from Irish Climate Analysis and Research UnitS (ICARUS) (Fealy and Sweeney 2008a). This data consists of statistically downscaled climate scenarios from three different Global Climate Models (GCMs) forced with two emissions scenarios. The GCMs employed are HadCM3, CGCM2 and CSIRO Mark 2. The future greenhouse gas emissions were taken from the IPPC Special Report on Emission Scenarios (SRES). The A2 (medium-high) and B2 (medium-low) emission scenarios predict both a more regional future development with either a more economical (A2) or environmental (B2) focus (IPCC 2000). Weights were based on the individual GCMs' ability to reproduce the observed climate. The coarse grid solution of the GCM data was then empirically statistically downscaled for the fourteen synoptic stations located throughout Ireland (Fealy and Sweeney 2008). The climatic data used in this study originates from the weighted ensemble mean data. The use of different GCMs and emission scenarios aims to incorporate the uncertainty associated with the utilisation of only one GCM or emission scenario in future models (Fealy and Sweeney 2008a). To capture the fine scale climatic variability within the catchment, the future weighted ensembles mean data was statistically downscaled to the synoptic station at Claremorris adjacent to the Moy catchment. No future data was available for humidity, wind speed and sunshine hours; therefore, the historical 30-year average had to be applied. However, these input parameters to the hydrological model showed very low model sensitivity in the previous investigation and were therefore assumed to have a minor influence to the streamflow outputs of the investigated catchments.

The result of the ensemble mean, produced by Fealy and Sweeney (2008b), suggests that by the 2020s, average seasonal temperatures across Ireland will increase by between $0.75-1.0^{\circ} \mathrm{C}$ relative to the 1961-1990 'control' period. By the 2050s, temperatures are expected to increase by $1.4-1.8^{\circ} \mathrm{C}$, reaching a $2.1-2.7^{\circ} \mathrm{C}$ temperature increase by the 2080 s (Fealy and Sweeney 2008b). These projected rates of climatic change are high compared to the rates of natural longterm climatic variations.

The precipitation scenario based on the ensemble mean suggests that winter precipitation will increase by the 2020s, by approximately $3 \%$ above the $1961-1990$ period. A similar order of decrease (approx. 3\%) was suggested in summer. By the 2050s, winter increase in precipitation is suggested to be $12 \%$, while the projected reductions in summer are also about $12 \%$. The seasonal changes in precipitation are further enhanced by the $2080 \mathrm{~s}$, with winter precipitation increases of $15 \%$ and summer reductions of $20 \%$ (Fealy and Sweeney 2007).

\subsection{Future Water Demand Scenarios}

There are several aspects influencing future water demand. In this study, four feasible 'what-if-scenarios' were investigated. No effect of climate change on water demand is assumed in all investigated scenarios. The hydrology of the scenarios is driven by the ensemble mean of future climate series. The population growth forecast was derived from the Irish Central Statistics Office's (CSO) Regional Population Projections. It is assumed that population growth does not vary across the scenarios. After the CSO's M2F1 Traditional scenario, the population is expected to increase by $1.5 \%$ per annum in the period to 2026 (CSO 2008). The projected trends are extrapolated from 2006 up to 2060. 
In order to assess the effect of the main components of water abstractions, four water demand scenarios were simulated:

- Scenario A - 'Business as Usual'. Current population trends are extrapolated into the future. Per capita water demand (150 litres), and supply infrastructure remain unchanged.

- Scenario B - 'Reduced Water Demand'. Increasing awareness in water conservation results in a stepwise water demand reduction to its 1996 level (140 litres per capita) by 2020. The level of unaccounted for water remains unchanged by $43 \%$.

- Scenario $C$ - 'Improved water supply infrastructure'. Stepwise-reduced leakage level from $43 \%$ to $25 \%$ by 2025 . Daily per capita water demand remains unchanged on its current level.

- Scenario D - Combination of Scenario B and Scenario C. Reduction of per capita water demand and leakage reduction, as described above.

\section{Results}

The four future water demand scenarios were assessed for the time periods of the 2020s and the 2050s. To derive a quantitative indication of the water resources pressure imposed on the examined areas within the Moy catchment, a water resource stress index was applied to analyse the model outputs. This physical index of vulnerability is the ratio of average water use divided by the average available water supply (Arnell 1999). The Water-Use-to-Resource-Ratio originates from a background paper to the Comprehensive Assessment of the Freshwater Resources of the World by the Stockholm Environmental Institute. The Comprehensive Assessment was initiated by the United Nations Commission for Sustainable Development in 1994 (Raskin 1997). The vulnerability index is divided into four categories as shown in Table 3. Generally, increasing levels of water stress indicate a higher water resource pressure on both the water quantity and water quality due to water abstraction.

Table 4 Sub-catchment size and population density

\begin{tabular}{cccc}
\hline Town Sub-Catchment & Size in $\mathrm{km}^{2}$ & Population & Population per $\mathrm{km}^{2}$ \\
\hline Balla & 79.25 & 316 & 3.99 \\
Ballina & 170.68 & 6852 & 40.15 \\
Castlebar & 79.87 & 6585 & 82.45 \\
Charlestown & 20.99 & 675 & 32.16 \\
Crossmolina & 153.52 & 1103 & 7.18 \\
Foxford & 1350.34 & 944 & 0.70 \\
Kilkelly & 42.37 & 258 & 6.09 \\
Kiltimagh & 125.99 & 917 & 7.28 \\
Knock & 2.12 & 575 & 271.23 \\
Swinford & 16.88 & 1386 & 82.11 \\
Tobercurry & 7.63 & 1089 & 142.73 \\
\hline
\end{tabular}

Initially, the results for the 2020s (2010-2039) and the 2050s (2040-2069) were analysed. There is a large spatial variability in the availability of water, which is expressed in varying water stress indices across the investigated sub-catchments. Only the four urban areas that showed the highest Water-Use-to-Resource-Ratio are given in 5. The bottom dotted horizontal line represents the $10 \%$ threshold for low water stress and the higher dashed line corresponds to medium water stress. The upper and lower error bars indicate the maximal or respectively the minimal obtained value over the 30 -year simulation period. 

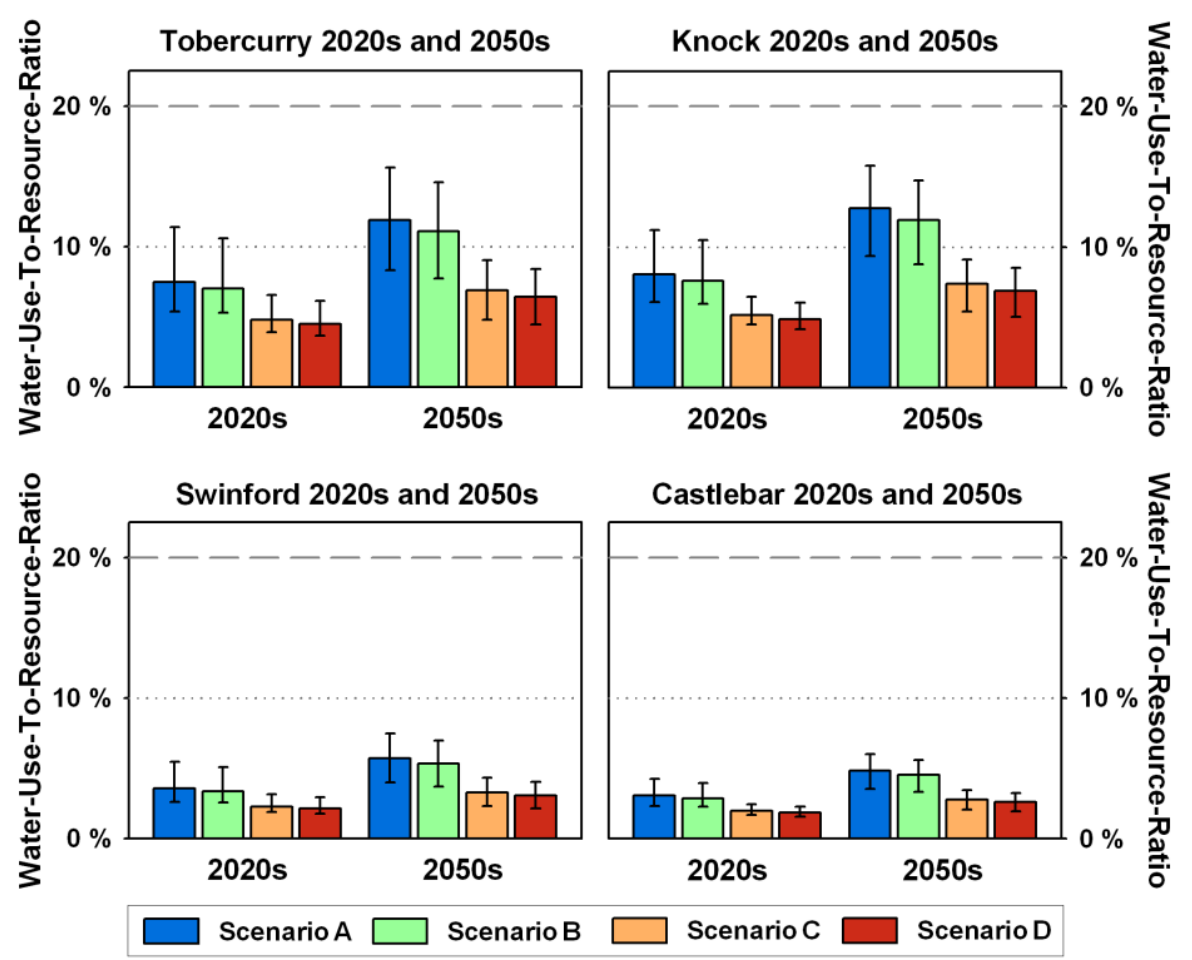

Fig. 5 Simulated percentage annual mean abstractions of annual available resource for the 2020s and 2050s. The bottom dotted horizontal line represents the $10 \%$ threshold for low water stress, the higher dashed line is the medium water stress. The upper and lower error bars indicate the annual maximal or respectively the minimal obtained value over the 30 -year simulation period

The simulation outcomes for the 2020s suggest that only two urban areas within the Moy catchment are likely to experience water stress for Scenarios A and B. In an average year, Knock and Tobercurry do not exceed the $10 \%$ low water stress, and only in some years go above the threshold. In Scenario C and D, no indication for water stress is given for any urban areas. For the 2050s, the mean values for Knock and Tobercurry indicate an increasing water stress for Scenario A and B, while for Scenario C and D the mean and the maximum values remain under the threshold of $10 \%$ average annual water abstraction to average available resource. The Water-Use-to-Resource gives a good first indication where future water resources might be under pressure. However, as the original Water-Use-to-Resource index is based on average annual runoff, an assessment of the vulnerability based on this index could result in misleading outcomes in regions with pronounced seasonality in their runoff generation. Therefore, the index was refined using monthly runoff totals, to take into account variations in summer and winter flow. To refine the findings for the Moy catchment, a monthly analysis of the water resource stress index was performed for the two decades 2020-2029 and 2050-2059. For both decades, the monthly average values for both abstraction and available resource were used (Figure 6). In the interest of clarity, the results for Scenario D are not provided in the detailed analysis. Scenario D is only slightly lower than Scenario C and falls within the same water stress category as Scenario C.

The model results for 2020-2029 suggest that only two urban areas within the Moy catchment are likely to experience Low or Medium Water Stress for all three scenarios. All other urban areas remain within the bands of Low or no water stress. Tobercurry and Knock exceed on average the $20 \%$ Medium Water Stress threshold during the summer months, for Scenario A and B. Only Tobercurry experienced high water stress in its extreme value for August in Scenario A, whereas Scenario C indicates Medium Water Stress for both urban areas. In an average year, Swinford only encounters Low Water Stress during July and August for Scenario 
A and B. All other urban areas within the Moy catchment undergo no water stress in all the scenarios during the decade 2020-2029.

In 2050-2059, the Water Stress Index increases by one category in Tobercurry, Knock, Swinford, Castlebar and Charlestown. On average, Tobercurry and Knock now experience High Water Stress and Swinford Medium Water Stress, whereas Castlebar encounters Low Water Stress during some summer months. Charlestown and the other six investigated urban areas (Balla, Ballina, Crossmolina, Foxford, Kilkelly, and Kiltimagh) were below the $10 \%$ threshold within all three scenarios for both investigated decades. Generally, for all scenarios in all sub-catchments, the Water-Use-to-Resource-Ratio is at its highest level during the summer months when river flows are at their lowest level. When comparing the individual results of the scenarios, it shows that Scenario $\mathrm{C}$ always has the lowest Water-Use-to-Resource-Ratio. For Castlebar the abstractions in Scenario C stay below the $10 \%$ low water stress threshold, whereas Scenarios A and B already experience low Water Stress the same period.

The urban areas that show a high consumption of the available water and hence vulnerability to water stress in the WEAP21 model are those of a high population per sub-catchment, and are all located upstream on a tributary of the River Moy (Table 4). For all four catchments, the population density is higher than 80 people per $\mathrm{km}^{2}$ of catchment area. The areas experiencing any kind of water stress in an average year are highlighted with shaded cells in Figure 7 . The results obtained suggest that location and catchment size are important factors with regard to how much water is available for consumption. Additionally, population density appears to be an important factor regarding the vulnerability to experience water stress.

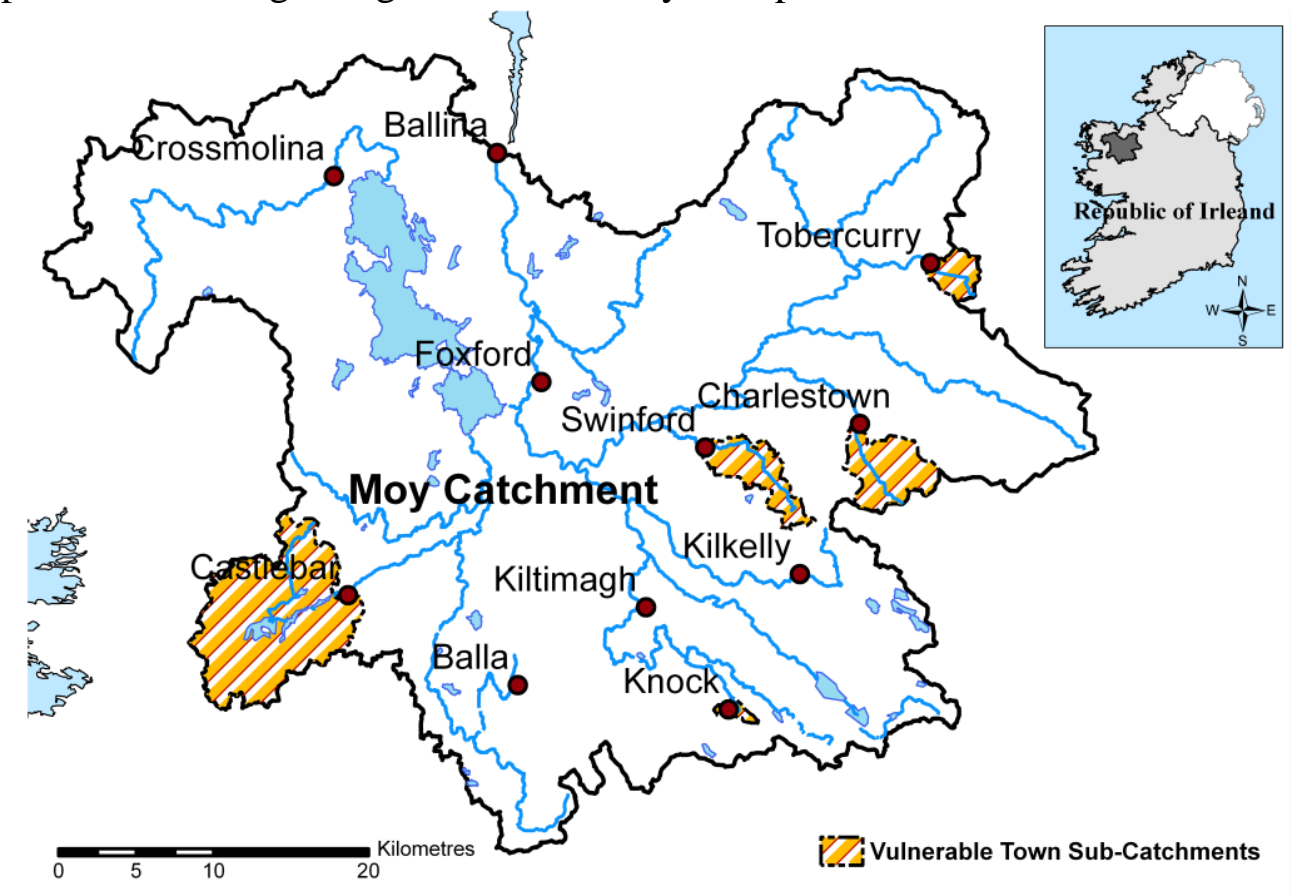

Fig. 7 Most vulnerable town sub-catchments in the Moy catchment

This example shows that both climatic and non-climatic factors put pressure on water resources. Critically, when water supply systems are already under pressure, a small change in the water resource availability due to climatic change or changes in water abstraction can have a significant impact. Conversely, robust systems can cope better with various pressures including large changes in water resource availability (Arnell 1998). The seven investigated urban areas, where no water stress was experienced during the entire study period, indicates the robustness of water supply in these locations. This illustrates that the translation from effect to impact is not linear or simple (Arnell 1998) and highlights the importance of an individual future water supply assessment, which takes both climatic change and the future development 
of non-climatic factors and the water supply system into account. Factors that are independent from climatic change include population changes, changes in water demand, legislative changes (e.g. the Water Framework Directive or introduction of water charges) as well as water infrastructural changes. The combination of these climatic and non-climatic factors will determine how vulnerable a water supply will be.

The results suggest that the high rate of abstraction might also cause problems in areas other than public water supply. Especially during the summer months, where flows are at their lowest level, water abstraction amounts to a high proportion of the total river flow. This will be likely to increase pressure on aquatic and environmental systems, as the flows are reduced by up to $30 \%$ of their normal flow volume. Furthermore, high water consumption in the tributaries raises the issue of water quality, because there is less water available to dilute any pre-treated wastewater that is released into the aquatic environment. If there is not enough water to dilute the returning wastewater, the river loses its ability to self-purify, resulting in depleted water quality. Moreover, the polluted water of the tributaries would flow into the River Moy, which is a SAC candidate of the E.U. Habitats Directive. The River Moy is one of Ireland's most important habitats for species like the Atlantic Salmon, which is also listed in the E.U. Habitats Directive. To ensure that these fish survive, and to safeguard the angling and tourism industries that are both economically very important to the Moy region, good water quality is essential. Overall, future water resource planning is required to prevent deterioration of water quality and to mitigate projected water stress posed on the aquatic system by various sources.

The characteristics of the water supply system are also important when assessing potential future water supply vulnerability. This is highlighted by Scenario C, which shows the significant effect of leakage reduction to reduce vulnerability to water stress. By reducing leakage from the current level of $43 \%$ to $25 \%$, an exceedance of the average $10 \%$ low water stress threshold is avoided in Swinford in 2020-2029 and in Castlebar in 2050-2059, reducing their vulnerability to climate change. 

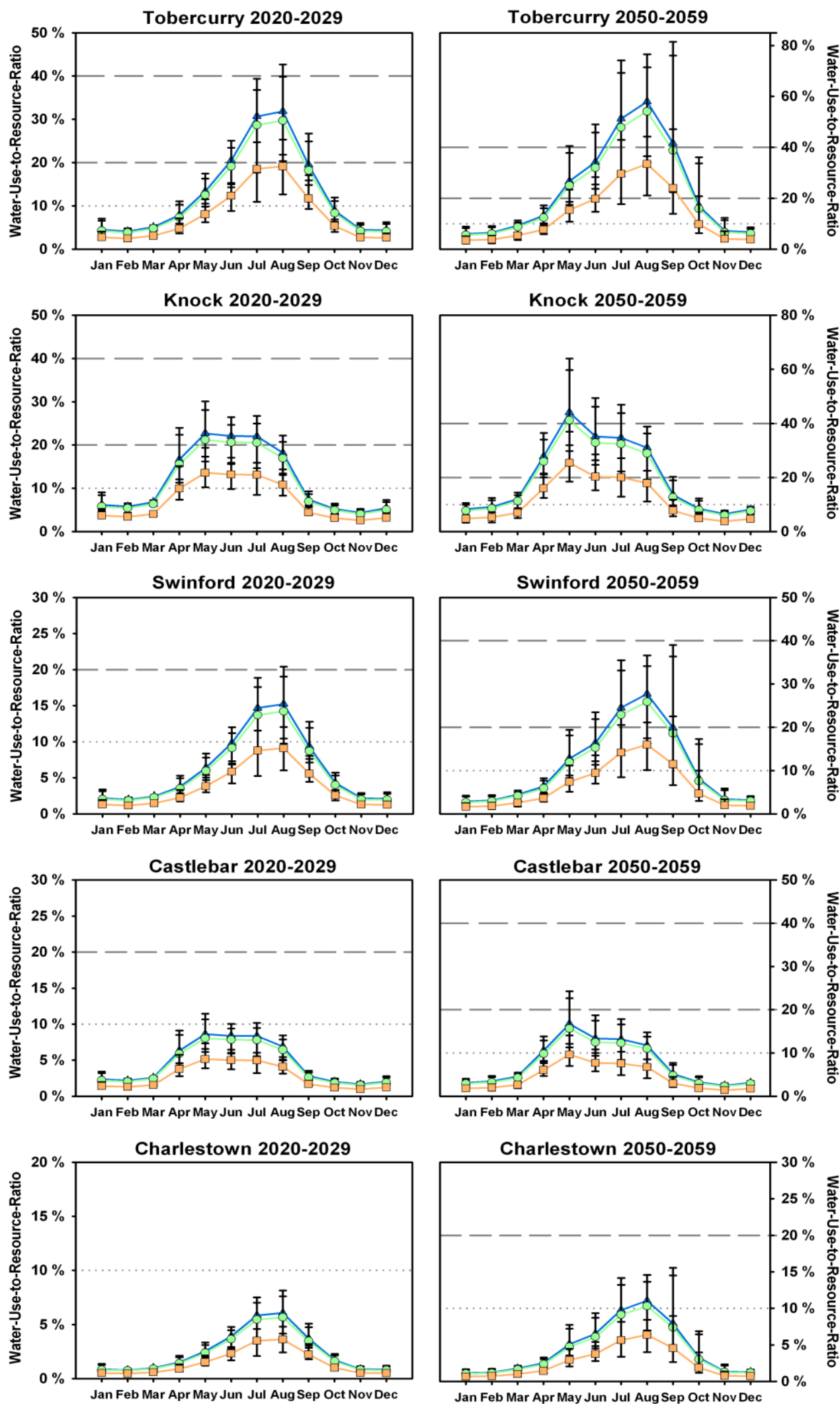

$\neg$ Scenario A $\quad \circ$ Scenario B $\quad \square-$ Scenario $C$

Fig. 6 Simulated percentage monthly mean abstractions of monthly available resource for 2020-2029 and 2050-2059. The bottom dotted horizontal line represents the $10 \%$ threshold for low water stress, the middle dashed line is the medium water stress threshold and the top horizontal line represents the high water stress threshold. The upper and lower error bars indicate the monthly maximal or respectively the minimal obtained value over the 30 -year simulation period 


\section{Discussion and Conclusion}

The above results highlight the importance of geographical location and seasonal variations in the assessment of future water supply impacts of climate change. Having identified the vulnerable areas and impacts in this study, it is apparent that further adaptation is needed. It is vital to start a discourse among stakeholders and decision makers, to develop and evaluate different adaptation options aiming to anticipate and mitigate detected vulnerabilities and therefore negative impacts of future change. Measures can be particular to climate adaptation but most can also be applied to other drivers of change and across a wide range of options. Considering adaptation measures and being aware of the uncertainties associated with future changes, proposed measures should for example favour strategies to increase robustness to uncertainty as suggested by Hallegatte (2009). For instance, applying a 'no-regrets' strategy implies that the measure yields benefits even if the anticipated changes do not occur. In case of the investigated Moy catchment and its sub-catchments the results indicate that reduction of the current water loss rate of $43 \%$ would be a favourable measure to mitigate future water stress in the public water supply sector. Leakage reduction can almost always be considered a very good investment from a cost-benefit analysis point-of-view (Hallegatte 2009). Another important strategy to increase robustness as recommended by Hallegatte (2009) and Frankenhauser (1999) is to favour reversible measures. This ensures that the ability to adjust to potential future changes is retained and the cost of inapropriate adaptation measures is kept at a minimum. An option that would only be reversible to a limited extent is for example the construction of a reservoir to retain water for the drier season. Building storage is an expensive option and has to be considered carefully to avoid wasting money if forecasts prove to be wrong. Failure to ensure the robustness of water supplies to climate change could have a huge impact on the large number of people dependent on these resources and could result in high costs to mitigate the effects. Therefore, an integrated approach to adaptation is needed. A first step for the Moy catchment in the direction of building adaptive capacity to future changes would be to encourage stakeholders to develop a water plan outlining management options to reduce vulnerability of people to the impacts of change. Building adaptive capacity involves a high risk from an economic perspective due to over or under design of measures but also offers the chance to obtain benefits from changing conditions.

The results of this work can provide a substantial platform on which to build further research to provide stakeholders and decision makers with the information for future planning and implementation of measures. In pursuing this research further, increased effort will be placed on incorporating the full range of uncertainty in model input. Overall, it is necessary to quantify the uncertainties and limitations associated with this study, to provide water-resource planners and policy makers with estimations on the reliability of the model output (Melching 1995; Wilby and Harris 2006). The integration of uncertainty analysis into modelling results and communicating the associated uncertainties and limitations can help to generate policy messages that are robust against uncertainty in an uncertain future (Brugnach et al. 2007).

\section{Acknowledgements}

Financial support from the Environmental Protection Agency (EPA) as part of the STRIVE project 2007-CCRP2.2.6 is fully acknowledged. Thanks also go to the Central Statistics Office (CSO), the Geological Survey of Ireland (GSI), Met Éireann, and the Office of Public Works (OPW), as well to the Western River Basin District (WRBD) for the supplied data. Thanks are also extended to the two anonymous reviewers who provided constructive comments. 


\section{References}

Arnell N (1998) Climate change and water resources in Britain. Climatic Change 39: 83-110. doi:10.1023/A:1005339412565

Arnell N (1999) Climate change and global water resources. Glob Environ Change 9: S31-S49. doi:10.1016/S09593780(99)00017-5

Arnell N (2006) The implications of climate change for hydrological regimes and water resources: an overview. In: National Hydrology Seminar 2006: Water Resources in Ireland and Climate Change, 14 November 2006 Tullamore, Ireland

Bahremand A, De Smedt F (2008) Distributed Hydrological Modeling and Sensitivity Analysis in Torysa Watershed, Slovakia. Water Resour Manage 22: 393-408. doi:10.1007/s11269-010-9584-1

Bates BC, Kundzewicz ZW, Wu S, Palutikof JP (eds.) (2008) Climate change and water. Technical paper of the Intergovernmental Panel on Climate Change. Geneva: IPCC Secretariat

Bronstert A (2004) Rainfall-runoff modelling for assessing impacts of climate and land-use change. Hydrol Process 18: 567-570. doi:10.1002/hyp.5500

Brugnach M, Tagg A, Keil F, de Lange WJ (2007) Uncertainty Matters: Computer Models at the Science-Policy Interface. Water Resour Manage 21: 1075-1090. doi:10.1007/s11269-006-9099-y

Bullock A, Acreman M (2003) The role of wetlands in the hydrological cycle. Hydrol Earth Syst Sc 7: 358-389

CSO (2006) Census 2006 reports. Central Statistics Office, Dublin. Available at: http://www.cso.ie/census/Census2006Results.htm. Accessed 19 August 2008

CSO (2008) Regional Population Projections. Central Statistics Office, Dublin. Available at: http://www.cso.ie/releasespublications/documents/population/current/poppro.pdf. Accessed 30 March 2009

CSO (2009) Census 2006 - Preliminary Report. Central Statistics Office, Dublin. Available at: http://www.cso.ie/census/documents/2006_prelim_press_release.pdf. Accessed 25 March 2009

Charlton R, Moore S (2003) The impact of climate change on water resources in Ireland. In: Sweeney J (ed) Climate change: Scenarios and impacts for Ireland - Final Report. Environmental Protection Agency, Johnstown Castle, Co. Wexford, Ireland, pp 81-102

Cunnane C, Regan S (1994) Hydrology and freshwater resource. In: McWilliams BE (ed) Climate Change: Studies of the implications for Ireland. Stationery Office, Dublin: Department of the Environment, pp 89-108.

Cycleau (2008) A profile of the Moy catchment - Technical summary. Ireland. Available at: http://www.cycleau.com/embedded_object.asp?docid=1004414. Accessed 08 July 2008

Dawson CW, Wilby RL (2001) Hydrological modelling using artificial neural networks. Prog Phys Geog 25: 80-108. doi:10.1177/030913330102500104

Doherty J, Johnston JM (2003) Methodologies for calibration and predictive analysis of a watershed model. J Am Water Resour As 29: 251-265. doi:10.1111/j.1752-1688.2003.tb04381.x

EPA (2007) The provision and quality of drinking water in Ireland - A report for the years 2006-2007. Environmental Agency, Dublin. Available http://www.epa.ie/downloads/pubs/water/drinking/DW\%20Report\%2020062.pdf. Accessed 20 August 2008

Evans M, Warburton J (2007) Geomorphology of upland peat: erosion, form, and landscape change. Blackwell Publishing, Malden, MA, USA

Fealy, R and Sweeney, J, (2007) Statistical downscaling of precipitation for a selection of sites in Ireland employing a generalised linear modelling approach. Int J Climatol: 27, 2089-2094. doi:10.1002/joc.1506

Fealy R, Sweeney J (2008a) Climate Scenarios for Ireland. In: Sweeney J (ed) Climate Change: Refining the Impacts for Ireland - Final Report. Environmental Protection Agency, Johnstown Castle, Co. Wexford, Ireland, pp 5-38

Fealy R, Sweeney J (2008b) Statistical downscaling of temperature, radiation and potential evapotranspiration to produce a multiple GCM ensemble mean for a selection of sites in Ireland. Irish Geogr 41: 1-27. doi:10.1080/00750770801909235

Forfás (2008) Assessment of water and waste water services for enterprise. Forfás, The National Policy and Advisory Board, Dublin.

Available at: http://www.envirocentre.ie/includes/documents/forfas080902_water_waste_water.pdf. Accessed 14 March 2009

Frankenhauser S (1999) Weathering climate change: some simple rules to guide adaptation decisions. Ecol Econ 30 : 67-78. doi: 10.1016/S0921-8009(98)00117-7

Hallegatte S (2009) Strategies to adapt to an uncertain climate change. Glob Environ Change 19: 240-247. doi:10.1016/j.gloenvcha.2008.12.003

IPCC (2000) Special Report on Emission Scenarios - Summary for Policymakers. A Special Report of IPCC Working Group III. Intergovernmental Panel on Climate Change, Geneva, Switzerland, Nakicenovic, Nebojsa; Swart,Rob

IPCC (2007) Climate Change 2007: Impacts, Adaptation and Vulnerability. Contribution of Working Group II to the Fourth Assessment Report of the Intergovernmental Panel on Climate Change. Cambridge University Press, Cambridge, UK, 976pp, Parry, M.L.; Canziani, O.F.; Palutikof, J.P.; van der Linden, P.J.; Handson, C.E. (eds.)

Klemeš V (1986) Operational testing of hydrological simulation models. Hydrol Sci J 31: 13-24. 
Lenhart T, Eckhardt K, Fohrer N, Frede H-G (2002) Comparison of two different approaches of sensitivity analysis. Phys Chem Earth 27: 645-654. doi:10.1016/S1474-7065(02)00049-9

Melching CS (1995) Reliability estimation. In: V.P. Singh (ed) Computer models of watershed hydrology. Water Resource Publication, Colorado, pp 69-115

Met Éireann (2008) 30 year averages . Dublin. Available at: http://www.met.ie/climate/30year-averages.asp. Accessed 24 July 2008

Murphy C, Charlton R (2006) The impact of climate change on water resources. In: Sweeney J (ed) Climate change: Refining the impacts - Final Report. Environmental Protection Agency, Johnstown Castle, Co. Wexford, Ireland, pp 39-81.

NPWS (2008) Special Areas of Conservation - Site Synopsis: River Moy. National Parks and Wildlife Service. Ely Place, Dublin, Ireland. Available at: http://www.npws.ie/en/media/Media,4225,en.pdf. Accessed 24 July 2008

O'Sullivan G (eds.) (1994) CORINE land cover project Ireland. Project report. Dublin: Ordnance Survey of Ireland

Raskin P (1997) Water Futures: Assessment of long-range patterns and problems. Background document to the Comprehensive Assessment of the Freshwater Resources of the World report. World Meteorological Organisation, Geneva, Switzerland. Available at: http://www.sei.se/mediamanager/documents/Publications/Watersanitation/urban_water_towards_health_sustainability.pdf. Accessed 24 August 2009

Slow the Flow (2009) Estimate household water consumption per day. Galway City Council. Available at: http://www.slowtheflow.ie/downloads/howmuchwater.pdf. Accessed 16 February 2009

Sorooshian S, Gupta VK (1995) Model calibration. In: V.P. Singh (ed) Computer models of watershed hydrology. Water Resource Publication, Colorado, pp 23-69

Steele-Dunne S, Lynch P, McGrath R, Semmler T et al. (2008) The impacts of climate change on hydrology in Ireland. J Hydrol 356: 28-45. doi:10.1016/j.jhydrol.2008.03.025

Wilby RL (2005) Uncertainty in water resource model parameters used for climate change impact assessment. Hydrol Process 19: 3201-3219. doi:10.1002/hyp.5819

Wilby RL, Harris I (2006) A framework for assessing uncertainties in climate change impacts: Low-flow scenarios for the River Thames, UK. Water Resour Res 42: W02419. doi:10.1029/2005WR004065

Working Group on Groundwater (2008) National recharge map of Ireland. Environmental Protection Agency and River Basin Districts Coordinating Authorities, Dublin

Yates D, Sieber J, Purkey D, Huber-Lee A (2005a) WEAP21-A demand-, priority- and preference-driven water planning model. Part 1: Model characteristics. Water Int 30: 487-500. doi:10.1080/02508060508691893

Yates D, Sieber J, Purkey D, Huber-Lee A (2005b) WEAP21-A demand-, priority- and preference-driven water planning model. Part 2: Aiding freshwater ecosystem service evaluation. Water Int 30: 501-521. doi:10.1080/02508060508691894 